\title{
Calcium fluoride based multifunctional nanoparticles for multimodal imaging
}

\author{
Marion Straßer ${ }^{*}, \ddagger 1,2$, Joachim H. X. Schrauth ${ }^{\ddagger 3,4}$, Sofia Dembski ${ }^{1,5,6}$, Daniel Haddad ${ }^{3,7}$, \\ Bernd Ahrens ${ }^{8,9}$, Stefan Schweizer ${ }^{8,9}$, Bastian Christ $^{5}$, Alevtina Cubukova ${ }^{5}$, \\ Marco Metzger ${ }^{5,6}$, Heike Walles ${ }^{5,6}$, Peter M. Jakob ${ }^{3,4}$ and Gerhard Sextl1,2
}

\section{Full Research Paper}

\section{Address:}

${ }^{1}$ Fraunhofer Institute for Silicate Research ISC, Neunerplatz 2, 97082 Wuerzburg, Germany, ${ }^{2}$ Department of Chemical Technology of Materials Synthesis, University of Wuerzburg, Roentgenring 11, 97070 Wuerzburg, Germany, ${ }^{3}$ MRB Research Center for Magnetic Resonance Bavaria, Am Hubland, 97074 Wuerzburg, Germany, ${ }^{4}$ Department of Experimental Physics 5 (Biophysics), University of Wuerzburg, Am Hubland, 97074 Wuerzburg, Germany, ${ }^{5}$ Translational Center Wuerzburg "Regenerative Therapies for Oncology and Musculosceletal Diseases”, Branch of Fraunhofer Institute for Interfacial Engineering and Biotechnology IGB, 97070 Wuerzburg, Germany, ${ }^{6}$ University Hospital Wuerzburg, Chair Tissue Engineering and Regenerative Medicine, Roentgenring 11, 97070 Wuerzburg, Germany, ${ }^{7}$ Magnetic Resonance and X-ray Imaging Department of Fraunhofer Development Center X-ray Technology EZRT, a division of Fraunhofer Institute for Integrated Circuits IIS, Am Hubland, 97074 Wuerzburg, Germany, ${ }^{8}$ South Westphalia University of Applied Sciences, Luebecker Ring 2, 59494 Soest, Germany and ${ }^{9}$ Fraunhofer Application Center for Inorganic Phosphors, Branch Lab of Fraunhofer Institute for Microstructure of Materials and Systems IMWS,

Luebecker Ring 2, 59494 Soest, Germany

Email:

Marion Straßer ${ }^{*}$ - marion.strasser@isc.fraunhofer.de

* Corresponding author $\ddagger$ Equal contributors

Keywords:

calcium fluoride nanoparticles; magnetic resonance imaging (MRI);

multifunctional nanoparticles; multimodal imaging; photoluminescence
Beilstein J. Nanotechnol. 2017, 8, 1484-1493.

doi:10.3762/bjnano.8.148

Received: 31 March 2017

Accepted: 22 June 2017

Published: 18 July 2017

This article is part of the Thematic Series "Nanomaterial-based cancer theranostics".

Guest Editor: V. Sivakov

(C) 2017 Straßer et al.; licensee Beilstein-Institut.

License and terms: see end of document.

\begin{abstract}
New multifunctional nanoparticles (NPs) that can be used as contrast agents (CA) in different imaging techniques, such as photoluminescence (PL) microscopy and magnetic resonance imaging (MRI), open new possibilities for medical imaging, e.g., in the fields of diagnostics or tissue characterization in regenerative medicine. The focus of this study is on the synthesis and characterization of $\mathrm{CaF}_{2}:\left(\mathrm{Tb}^{3+}, \mathrm{Gd}^{3+}\right)$ NPs. Fabricated in a wet-chemical procedure, the spherical NPs with a diameter of 5-10 nm show a crystalline structure. Simultaneous doping of the NPs with different lanthanide ions, leading to paramagnetism and fluorescence, makes them suitable for MR and PL imaging. Owing to the $\mathrm{Gd}^{3+}$ ions on the surface, the NPs reduce the MR $T_{1}$ relaxation time constant as a function of their concentration. Thus, the NPs can be used as a MRI CA with a mean relaxivity of about $r=0.471 \mathrm{~mL} \cdot \mathrm{mg}^{-1} \cdot \mathrm{s}^{-1}$.
\end{abstract}


Repeated MRI examinations of four different batches prove the reproducibility of the NP synthesis and determine the long-term stability of the CAs. No cytotoxicity of NP concentrations between 0.5 and $1 \mathrm{mg} \cdot \mathrm{mL}^{-1}$ was observed after exposure to human dermal fibroblasts over $24 \mathrm{~h}$. Overall this study shows, that the $\mathrm{CaF}_{2}:\left(\mathrm{Tb}^{3+}, \mathrm{Gd}^{3+}\right) \mathrm{NPs}$ are suitable for medical imaging.

\section{Introduction}

In recent years, medical imaging has become an important approach in the fields of diagnostics, therapy and regenerative medicine. Besides the classical technology of X-ray examination, contrast-rich methods such as computed tomography (CT), magnetic resonance imaging (MRI), positron emission tomography (PET) and ultrasonic techniques are being used increasingly for imaging soft tissue, e.g., cartilage imaging in progressive osteoarthritis. Advantages of different imaging techniques are used individually or combined to obtain a more detailed answer for medical questions and, thus, to reach a rapid and precise diagnosis. CT and MRI provide essentially morphological information and information on tissue structures and changes. Nuclear medicine procedures such as PET visualize metabolic processes and provide information on biochemical parameters. The optical imaging techniques such as fluorescence (PL) microscopy allow for a direct transfer of biological knowledge about cells in the in vivo application, e.g., endogenous regulation of transcription [1]. In this context, greater treatment success can be achieved through the combination of several detection methods. Contrast agents (CAs) are used to improve representation of structures and functions of the body by increasing the sensitivity and reducing the ambiguity in imaging techniques. Since the imaging techniques are based on different physical principles, different CAs are required. For the patient, this is associated with extended examination times, multiple injections and repeated contact with chemical substances. This results in an increased workload for the medical staff and an uncomfortable screening procedure for the patient. Therefore, it is desirable to develop a combined CA that is injected only once and then detected using different diagnostic methods with a higher comparability.

The production of CAs on the basis of nanoparticles (NPs) shows promise, as already examined on the infected myocardium [1-3]. Each imaging modality has its advantages and disadvantages. The integration of multiple functions into one NP system yields synergies and allows for a precise and fast diagnosis of diseases. Recently, various multimodal imaging probes on the basis of different functional NPs were fabricated for more accurate imaging and diagnosis [2]. One possibility is the synthesis of core/shell-structured NPs. Core and shell materials can be matched individually to specific detection methods. For example, the coating of a magnetic core with silicates or polymer shells doped with organic fluorophores or quantum dots (QDs) allows for the detection of NPs by MRI and PL [4].
Several successive shells can be designed of different inorganic materials. In this context, the following particle systems may be mentioned $\mathrm{Gd}_{2} \mathrm{O}\left(\mathrm{CO}_{3}\right)_{2} \cdot \mathrm{H}_{2} \mathrm{O} / \mathrm{SiO}_{2} / \mathrm{Au}, \mathrm{Fe}_{3} \mathrm{O}_{4} / \mathrm{C} / \mathrm{Ag}$ and $\mathrm{Fe}_{3} \mathrm{O}_{4} /$ $\mathrm{SiO}_{2} / \mathrm{Y}_{2} \mathrm{O}_{3}:\left(\mathrm{Yb}^{3+}, \mathrm{Er}^{3+}\right)$ core/shell NPs [5-7]. Another possibility is to create multifunctional NPs by precipitation and simultaneous doping of the NP matrix with various ions [8,9]. Due to their co-doping with lanthanide ions, NPs on the basis of calcium phosphate or gadolinium oxide are also detectable by MRI and PL [10-13].

In recent years, fluorides have attracted considerable interest owing to their unique optical properties [14]. Fluoride NPs were used in lighting, optical amplification and lasing [14] and are well-known strategic materials in optical and photonic technologies in general. Furthermore, they combine high quantum efficiency with favorable chemical and mechanical properties. They seem to be perfect materials as fluorescence host matrix owing to their low phonon energies and they subsequently minimize the quenching of the excited state of rare-earth ions. In contrast to chloride or bromide hosts, fluorides are completely air stable materials $[15,16]$.

Other than fluoride NP systems doped with rare earth elements, such as $\mathrm{LaF}_{3}: \mathrm{Ln}^{3+}, \mathrm{CeF}_{3}: \mathrm{Tb}^{3+}, \mathrm{NaYF}_{4}:\left(\mathrm{Yb}^{3+}, \mathrm{Er}^{3+}\right)$, $\mathrm{NaGdF}_{4}:\left(\mathrm{Yb}^{3+}, \mathrm{Er}^{3+}\right)$, which were actively investigated during last decades for biomedical applications [17-22], alkaline earth metal fluorides such as $\mathrm{CaF}_{2}$ received little attention. There are only sporadic suggestions for the synthesis and application of this NP system as a labeling material. To date, $\mathrm{CaF}_{2}$ has attracted most attention with respect to UV lithography, UV-transparent optical lenses, the surface conditioning of glass, the promotion of biocompatible agents for bone and teeth reconstruction [23]. Calcium fluoride exhibits a wide transparent spectral window (190-1100 nm), large band gap (approx. $12 \mathrm{eV}$ ), low refractive index and low phonon energy [14].

Because of the high stability and flexibility of the fluorite structure, a number of various ionic substitutions can also be integrated in the $\mathrm{CaF}_{2}$ lattice [24]. Various methods have been reported for the preparation of rare-earth doped $\mathrm{CaF}_{2} \mathrm{NPs}$ such as co-precipitation [14,15,24-26], hydrothermal methods [27-29], flame synthesis [30], microemulsion methods [31,32] and a fluorolytic sol-gel process [33]. The stability and biocompatibility of $\mathrm{CaF}_{2}$ makes it an attractive material for biomedical applications $[28,29]$. In addition, due to the high capacity to 
accept lanthanide ions, $\mathrm{CaF}_{2}$ is suitable for the preparation of CAs for multimodal imaging [24].

In this study, we report on synthesis and characterization of multifunctional NPs based on $\mathrm{CaF}_{2}$. These NPs are produced by wet-chemical synthesis and doped with multiple ions leading to paramagnetism and fluorescence, making them suitable for $T_{1}$-weighted MRI and PL microscopy. The characterization of the resulting NPs is carried out by using transmission electron microscopy (TEM), X-ray diffraction (XRD) analysis, inductively coupled plasma optical emission spectrometry (ICPOES), and photoluminescence (PL) spectroscopy. The capability of these NPs to be used as positive CAs for MRI was also investigated. In addition, the cytotoxicity of the NPs was tested by a cell culture based viability assay.

\section{Results and Discussion \\ Synthesis and characterization of the multi- functional nanoparticles}

The synthesis of the $\mathrm{CaF}_{2}:\left(\mathrm{Tb}^{3+}, \mathrm{Gd}^{3+}\right)$ NPs was carried out in analogy to the reported wet-chemical procedure that is based on a co-precipitation process in ethanol [26]. Moreover, the NPs were doped with different lanthanide ions $\left(\mathrm{Tb}^{3+}, \mathrm{Gd}^{3+} ; 1 \mathrm{~mol} \%\right.$ based on Ca content) to guarantee a PL and MR activity. $\mathrm{CaCl}_{2}$, $\mathrm{Tb}\left(\mathrm{NO}_{3}\right)_{3} \cdot 5 \mathrm{H}_{2} \mathrm{O}, \mathrm{GdCl}_{3} \cdot 6 \mathrm{H}_{2} \mathrm{O}$ and $\mathrm{NH}_{4} \mathrm{~F}$ were used as reactants to prepare the NPs by a low-temperature single-step approach. $\mathrm{CaCl}_{2}$ and $\mathrm{NH}_{4} \mathrm{~F}$ exhibit a significant solubility in water, but $\mathrm{CaF}_{2}$ is insoluble in water and precipitates from aqueous solution. It is difficult to control the particle growth in aqueous solution and therefore the synthesis of the doped NPs is carried out in ethanol. This solvent contains a very low $\mathrm{F}^{-}$ion concentration because of the low solubility of $\mathrm{NH}_{4} \mathrm{~F}$ in an ethanol solution and therefore the particle growth is slower [26].

The inset in Figure 1 shows the TEM micrograph of the $\mathrm{CaF}_{2}:\left(\mathrm{Tb}^{3+}, \mathrm{Gd}^{3+}\right) \mathrm{NPs}$. The NPs possess a spherical shape with an average diameter of 5-10 $\mathrm{nm}$. The results of the dynamic light scattering (DLS) show that these NPs are non-agglomerated and exhibit a narrow size distribution and a hydrodynamic particle diameter of 25-30 nm (number- and volume-weighted, Figure 1, see also DLS of the stabilized NPs, Figure S1, Supporting Information File 1 (number-weighted)).

For the determination of the MR relaxivity of the NPs, we use the hydrodynamic particle diameter from the DLS, because the correlation time between them and the surrounding water molecules depends on the tumbling of the NPs, which is influenced by their size and their morphology.

Figure 2 displays a selected XRD pattern of the crystalline $\mathrm{CaF}_{2}:\left(\mathrm{Tb}^{3+}, \mathrm{Gd}^{3+}\right) \mathrm{NPs}$, all other samples exhibit the same ten-

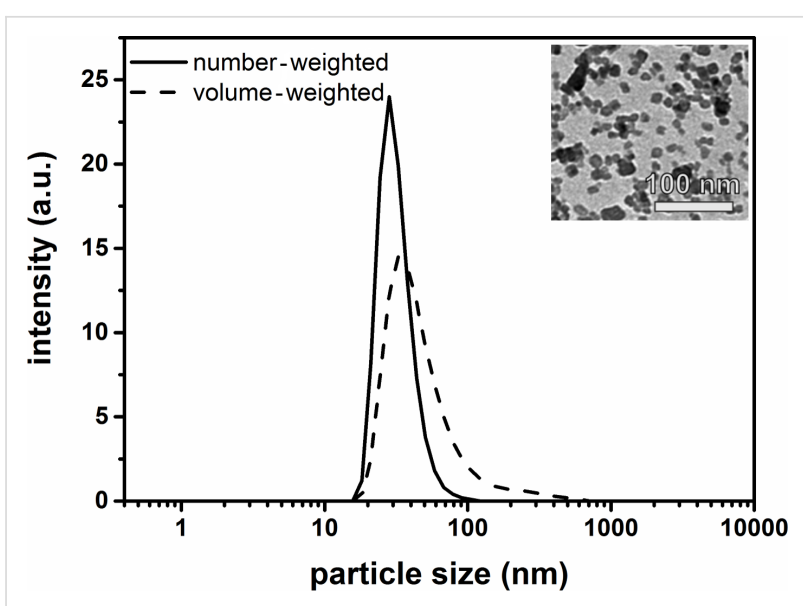

Figure 1: DLS measurement of the $\mathrm{CaF}_{2}:\left(\mathrm{Tb}^{3+}, \mathrm{Gd}^{3+}\right)$ NPs (numberand volume-weighted). Inset: TEM micrograph of the same particles. The size of the NPs is in the range of $5-10 \mathrm{~nm}$ and they have a spherical shape.

dency. The phase analysis indicates that the obtained product shows prominent peaks well accordant with the JCPDS standard card (Joint Committee on Powder Diffraction Standards, Powder Diffraction File: 035-0816) of fluorite $\left(\mathrm{CaF}_{2}\right)$. Moreover, there are reflexes of $\mathrm{NH}_{4} \mathrm{Cl}$ detectable which come from the educts. Doping with multiple ions does not have influence on the formation of calcium fluoride crystal lattice.

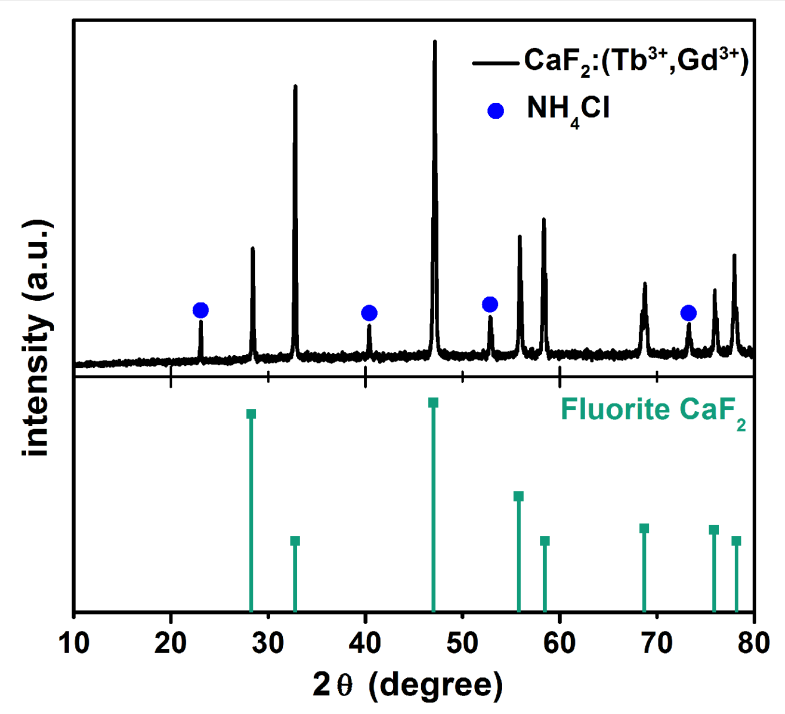

Figure 2: In the upper part, the XRD pattern of the $\mathrm{CaF}_{2}:\left(\mathrm{Tb}^{3+}, \mathrm{Gd}^{3+}\right)$ NPs $\left(d=5-10 \mathrm{~nm}\right.$, doping concentration of $\mathrm{Tb}^{3+}$ and $\left.\mathrm{Gd}^{3+}: 1 \mathrm{~mol} \%\right)$ is plotted. Below a reference spectrum from the database JCPDS (Joint Committee on Powder Diffraction Standards, Powder Diffraction File: 035-0816) is shown. The reflexes of both spectra appear at the same diffraction angles $2 \theta$, which indicates the crystalline structure $\left(\mathrm{CaF}_{2}=\right.$ fluorite $)$ of the NPs. The blue points mark the peaks of $\mathrm{NH}_{4} \mathrm{Cl}$.

Since the XRD measurement only implies that the NPs have the crystalline structure of fluorite and nothing about the incorpora- 
tion of the lanthanide ions, we analyze the composition of our nanoparticles further by means of ICP-OES. Table 1 shows the outcome of a representative sample.

\begin{tabular}{|c|c|c|}
\hline element & $\begin{array}{l}\text { amount of substance } \\
(\mathrm{mol})\end{array}$ & doping ( $\mathrm{mol} \%$ ) \\
\hline $\mathrm{F}$ & 0.46 & \\
\hline $\mathrm{Ca}$ & 0.20 & \\
\hline $\mathrm{Tb}$ & 0.02 & 0.87 \\
\hline $\mathrm{Gd}$ & 0.02 & 0.92 \\
\hline
\end{tabular}

The obtained ratio of calcium and the lanthanide ions to fluoride $((\mathrm{Ca}+\mathrm{Ln}) / \mathrm{F}=0.52)$ is an additional confirmation of the crystalline structure of fluorite with a composition of $\mathrm{CaF}_{2}$. The doping levels are in the intended range of $1 \mathrm{~mol} \%$. However, there is a lower content of $\mathrm{Tb}^{3+}$ and $\mathrm{Gd}^{3+}$ (total amount of $1.83 \mathrm{~mol} \%$ ), which indicates a higher reaction rate of calcium compared to the dopants. This could be correlated to the different ion radii.

\section{Photoluminescence spectroscopy}

With respect to a later usage of our NPs as a contrast agent for PL we have also investigated the optical properties. Since terbium and its optical properties are extensively described in the literature [34-37], we use it as a model system in order to proof the integration of the ions in the calcium fluoride lattice (proof of principle). For a later clinical usage certainly we have to exchange terbium for a NIR dye or something similar because of the high sensitivity of living tissues towards UV light. In Figure 3 the emission spectrum of $\mathrm{CaF}_{2}:\left(\mathrm{Tb}^{3+}, \mathrm{Gd}^{3+}\right)$ NPs at an excitation wavelength of $\lambda_{\text {exc }}=254 \mathrm{~nm}$ is shown. There are several maxima (490, 542, 586 and $622 \mathrm{~nm})$, which represent the $\mathrm{Tb}^{3+}$-related transitions from the ${ }^{5} \mathrm{D}_{4}$ excited state to the energy levels indicated [34,35]. The main emission line can be assigned to the ${ }^{5} \mathrm{D}_{4} \rightarrow{ }^{7} \mathrm{~F}_{5}$ transition of $\mathrm{Tb}^{3+}$ and causes an intense emission in the green spectral range $(\lambda=542 \mathrm{~nm}$, Figure 3) $[36,37]$. Additionally, to XRD and ICP-OES measurements this was a confirmation of a successful integration of the $\mathrm{Tb}^{3+}$ ions in the calcium fluoride host lattice.

\section{Magnetic resonance imaging}

MRI is a non-invasive method that is optimized for soft tissue imaging in daily clinical use. Paramagnetic CAs are often used to reduce the measurement period or to gain higher signal-tonoise-ratios (SNR) which allows for improved diagnosis. Within this study, the capability of $\mathrm{CaF}_{2}:\left(\mathrm{Tb}^{3+}, \mathrm{Gd}^{3+}\right) \mathrm{NPs}$ to be used as positive CAs for MRI was investigated. To this end, dif-

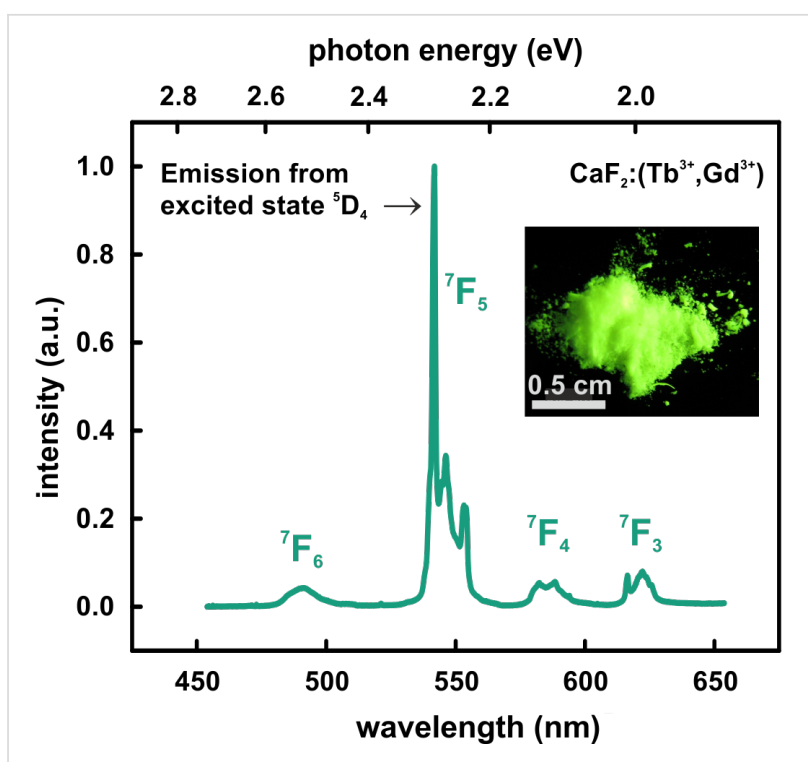

Figure 3: Normalized photoluminescence spectrum of $\mathrm{CaF}_{2}:\left(\mathrm{Tb}^{3+}, \mathrm{Gd}^{3+}\right) \mathrm{NPs}$ at an excitation wavelength of $\lambda_{\text {exc }}=254 \mathrm{~nm}$ The emission spectrum shows several maxima $(490,542,586$ and $622 \mathrm{~nm}$ ), which represent the $\mathrm{Tb}^{3+}$-related transitions from the ${ }^{5} \mathrm{D}_{4}$ excited state to the energy levels indicated. The maximum intensity occurs in the green spectral range at a wavelength of $\lambda=542 \mathrm{~nm}$. Inset: $\mathrm{CaF}_{2}:\left(\mathrm{Tb}^{3+}, \mathrm{Gd}^{3+}\right) \mathrm{NP}$ powder under UV light excitation $\left(\lambda_{\text {exc }}=254 \mathrm{~nm}\right)$. The green luminescence matches the maximum of the emission spectrum.

ferent NP samples dispersed in water were characterized by MRI. To determine the contrast effect, NP dispersions of various concentrations $\left(0.4-18.2 \mathrm{mg} \cdot \mathrm{mL}^{-1}\right)$ were analyzed.

\section{$\mathrm{CaF}_{2}:\left(\mathrm{Tb}^{3+}, \mathrm{Gd}^{3+}\right) \mathrm{NPs}$ as MRI contrast agent}

Doping with $\mathrm{Gd}^{3+}$ ions leads to paramagnetism of the $\mathrm{CaF}_{2}$ NPs. Because of this the NPs can be used as a $T_{1}$ CA. Additionally, there should be also an attenuation of the CT signal, which allows for the application as a CT CA. This property is already closer investigated in an ongoing study and will be shown in an additional publication in the future.

The $T_{1}$-weighted image of the $\mathrm{CaF}_{2}:\left(\mathrm{Tb}^{3+}, \mathrm{Gd}^{3+}\right)$ NPs with concentrations in the range from 0.4 to $18.2 \mathrm{mg} \cdot \mathrm{mL}^{-1}$ is shown in Figure 4a. Due to the different concentrations of the samples, the $T_{1}$ relaxation time constants vary and therefore, different signal intensities are observable at different time points.

To evaluate the potential CA not only on a qualitative basis, it is required to determine the efficiency quantitatively. First, it is necessary to measure the signal intensity at different time points and fit these intensities with a mono-exponential function. A $T_{1}$-map can be calculated (cf. Figure $4 \mathrm{~b}$ ). In this batch, the $T_{1}$ values of the NPs vary from 137 to $1633 \mathrm{~ms}$ with decreasing concentrations. Plotting the relaxation rate $R_{1}$ (inverse relaxation time $T_{1}$ ) over the concentration of the samples, the relax- 


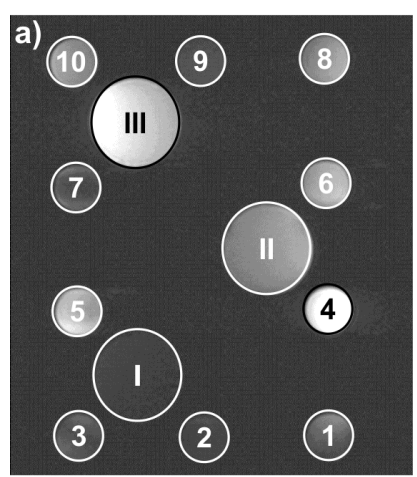

$$
0
$$

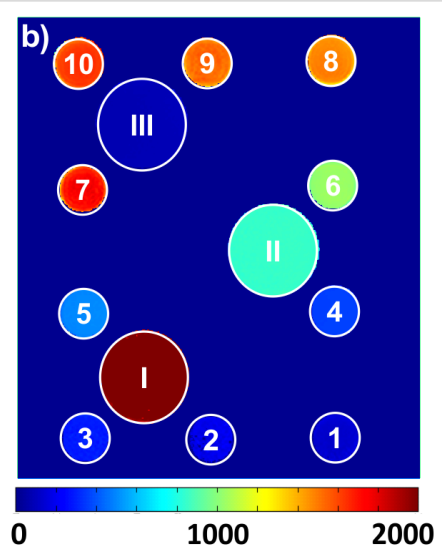

relaxation time $T_{1}(\mathrm{~ms})$

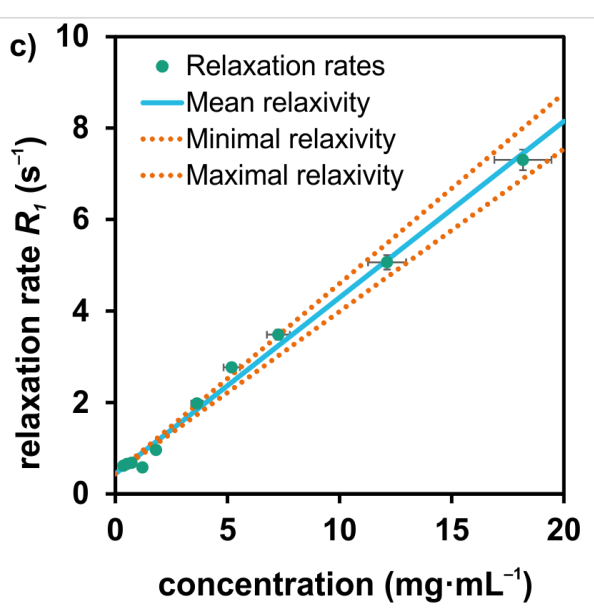

Figure 4: a) $T_{1}$-weighted MR image of the $\mathrm{CaF}_{2}:\left(\mathrm{Tb}^{3+}, \mathrm{Gd}^{3+}\right) \mathrm{NPs}$ with different concentrations in the range from 0.4 to $18.2 \mathrm{mg} \cdot \mathrm{mL}^{-1}(1-10)$. I-III are reference samples of water and two concentrations of Magnevist. The different concentrations result in observable differences of the signal intensities. In b) the following $T_{1}$-map with a corresponding color range from 0 to $2000 \mathrm{~ms}$ is shown. c) The relaxivity $\left(r=0.385 \pm 0.030 \mathrm{~mL} \cdot \mathrm{mg}^{-1} \cdot \mathrm{s}^{-1}\right)$ arises from the slope by plotting the relaxation rates over the concentrations. The errors of the relaxivity are given by the minimal and maximal slope.

ivity $r$ arises from the slope of the linear fit (cf. Equation 1, Figure 4c)

$$
R_{1}(c)=R_{1}(c=0)+r \cdot c .
$$

The relaxivity indicates the efficiency of the CA. The most common CA in clinical applications is Magnevist (gadopentetate dimeglumine) with a relaxivity of $4.89 \mathrm{~mL} \cdot \mathrm{mg}^{-1} \cdot \mathrm{s}^{-1}$ [38]. In this study, Magnevist was used as a reference in each measurement. Generally, the relaxivity is given in liters per mole per second. To compare the obtained relaxation rates from our NP dispersions with the relaxation rate from Magnevist we should convert the units because Magnevist is a complex with only one $\mathrm{Gd}^{3+}$ ion. In contrast, there are many $\mathrm{Gd}^{3+}$ ions in one NP evoking the MR activity. Unfortunately, we cannot quantify by now the exact amount of $\mathrm{Gd}^{3+}$ ions on the surface. The ICP-OES measurements (cf. Table 1) tell us how many $\mathrm{Gd}^{3+}$ ions are within the NPs in total, but most probably only the $\mathrm{Gd}^{3+}$ on the surface are responsible for the contrasting effect. Therefore, we convert the units into milliliters per milligram per second (for the calculation see Figure S2, Supporting Information File 1).

The relaxation rates obtained have a standard deviation of 3.1\%. This value is used for the uncertainty of the MRI measurement itself and therefore also for the relaxation rates of the NPs. For acquiring the relaxivity of the NPs, an additional source of error is the uncertainty of the concentration of each sample. Determining the concentration, a gravimetrical measurement was carried out three times for each sample. The maximum deviation of the values was about $\pm 7 \%$, because of different error sources such as weighing or pipetting of the small sample volumes. The error of the relaxivity is given by the resulting minimal and maximal slope (Figure 4c).

\section{Reproducibility of the MR relaxivity}

To test the reproducibility of the CA efficiency, four batches of NPs were produced and their relaxivities were determined. These results are shown in Table 2 and Figure 5.

The first row of Table 2 and the green bars of Figure 5 represent the results of the measurements directly after fabrication. All results overlap with their error bars and additionally the mean value lies also within the ranges of all batches. Therefore, the relaxivities of all batches are comparable with each other indicating a high reproducibility of the synthesis procedure. This matches to the above described results of TEM, DLS and ICPOES examinations.

\section{Long-term stability}

The long-term stability of the relaxivity over time was examined. All batches were investigated nine months after fabrica-

\begin{tabular}{|c|c|c|c|c|c|}
\hline & batches & 1 & 2 & 3 & 4 \\
\hline \multirow{2}{*}{$\begin{array}{l}\text { relaxivity } r \\
{\left[\mathrm{~mL} \cdot \mathrm{mg}^{-1} \cdot \mathrm{s}^{-1}\right]}\end{array}$} & as prepared & $0.438 \pm 0.044$ & $0.443 \pm 0.044$ & $0.522 \pm 0.052$ & $0.451 \pm 0.045$ \\
\hline & nine months after fabrication & $0.385 \pm 0.038$ & $0.388 \pm 0.039$ & $0.467 \pm 0.046$ & $0.400 \pm 0.040$ \\
\hline
\end{tabular}

Table 2: Relaxivities of four different batches: as prepared (row 1) and nine months after fabrication (row 2). 


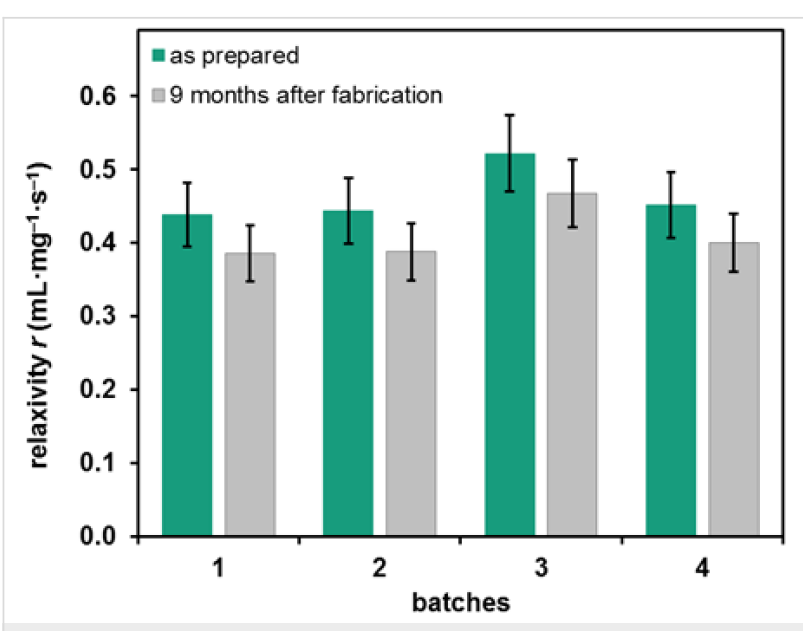

Figure 5: Relaxivity values of the four batches as prepared (green) and nine months (grey) after fabrication. Considering the error bars, the measured relaxivities directly after the preparation overlap with each other. After nine months a decrease of the relaxivity of each batch can be observed.

tion. These results are also shown in Table 2 and Figure 5. It is apparent that all relaxivities decrease over time. The difference between both groups (all batches as prepared and nine months after fabrication), which was tested with a $t$-test, is highly significant $(p<0.01)$. This decrease of the relaxivities cannot be explained with the deviation of the MR measurements. More likely, this trend is triggered by an agglomeration of the NPs. This results in a lower concentration of $\mathrm{Gd}^{3+}$ on the surface of the NPs, which leads to a lower interaction with the surrounding protons, implying a higher relaxation time constant and consequently a lower relaxivity. On average, all batches decrease about $11.6 \%$ after nine months. Through an examination of the vertical distribution of the $T_{1}$ relaxation time constants in the probing tubes a sedimentation of the NPs or a decrease of the relaxivity can be excluded. Also, a decomposition of the $\mathrm{NPs}$, resulting in an increase of the free $\mathrm{Gd}^{3+}$ concentration within the solution and therefore an increase of the relaxivity, does not take place. This is another very important property of our CA, because of the toxicity of free $\mathrm{Gd}^{3+}$ ions.

\section{Biocompatibility}

In general, NPs without appropriate surface modification have a disposition to agglomerate and sediment subsequently under physiological conditions because of their $\mathrm{pH}$ value and salt content [39-41]. One crucial requirement for the application of NPs in cell-culture experiments or animal testing is the stabilization in physiological media. In contrast to an electrostatically stabilization of the NPs, for example by capping the $\mathrm{CaF}_{2}$ NPs surface with citrate groups [28], we ensure the stability of the NPs in serum-containing cell-culture media in an electrosterical way. To this end, a polymer consisting of a polycarboxylate ether backbone and polyethylene oxide side chains bound to the backbone as esters (Melpers ${ }^{\circledR} 2450$ ), which can be considered as non-toxic [42], is adsorbed via Coulomb attraction between the negatively charged backbone on the positively charged NP surface [43]. As shown in photographs of bare and Melpers ${ }^{\circledR} 2450$-stabilized NPs dispersed in cell-culture medium containing fetal calf serum (FCS) (cf. Figure 6a), bare NPs start to sediment after $24 \mathrm{~h}$ and the stabilized sample remains clear. Additionally, the colloidal stability was monitored by UV-vis spectroscopy. The absorbance measurements $\left(\lambda_{\mathrm{abs}}=700 \mathrm{~nm}\right)$ of stabilized and non-stabilized $\mathrm{CaF}_{2}:\left(\mathrm{Tb}^{3+}, \mathrm{Gd}^{3+}\right)$ NPs in FCScontaining cell-culture medium over a period of $24 \mathrm{~h}$ is shown in Figure 6b. In contrast to non-stabilized NPs, the stabilized sample shows hardly any change in absorbance over a period of $24 \mathrm{~h}$. The measured curve of non-stabilized NPs decreases within $2 \mathrm{~h}$ because of light scattering on NP agglomerates. Light-microscopy images of dispersions of stabilized and nonstabilized $\mathrm{CaF}_{2}:\left(\mathrm{Tb}^{3+}, \mathrm{Gd}^{3+}\right)$ NPs in FCS-containing cell-culture medium are given in Figure S3 (Supporting Information File 1).
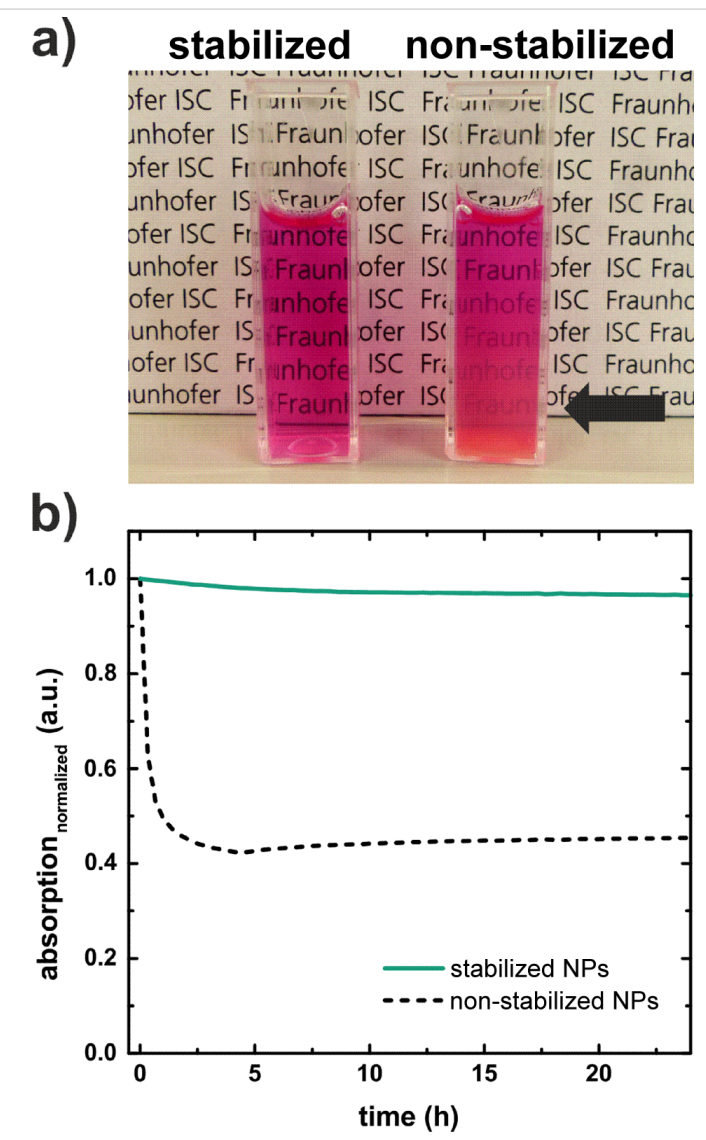

Figure 6: Sedimentation study of the $\mathrm{CaF}_{2}:\left(\mathrm{Tb}^{3+}, \mathrm{Gd}^{3+}\right) \mathrm{NPs}$ ( $5 \mathrm{mg} \cdot \mathrm{mL}^{-1}$ ) in Dulbecco's Modified Eagle's Medium (DMEM) with $10 \%$ FCS stabilized with Melpers ${ }^{\circledR} 2450$ and non-stabilized: a) photographs of the stabilized NPs and the non-stabilized NPs $24 \mathrm{~h}$ after dispersing the NPs in FCS-containing cell-culture medium and b) absorbance measurement $\left(\lambda_{\mathrm{abs}}=700 \mathrm{~nm}\right)$ of the samples over a period of $24 \mathrm{~h}$. 
Finally, the viability of human dermal fibroblasts (hdF) after treatment with the NPs stabilized with Melpers ${ }^{\circledR} 2450$ for $24 \mathrm{~h}$ was evaluated. Therefore, the CellTiter-Glo assay was used [44], a method that is based on the quantification of adenosine-5'-triphosphate (ATP), which signals the presence of metabolically active cells. Adding the CellTiter-Glo reagent directly to hdF results in cell lysis and generates a luminescent signal directly proportional to the amount of the ATP concentration. The particle samples with a cellular viability over $80 \%$ can be classified as biocompatible. We have chosen concentrations of $\mathrm{CaF}_{2}:\left(\mathrm{Tb}^{3+}, \mathrm{Gd}^{3+}\right) \mathrm{NPs}$ between 0.5 and $1 \mathrm{mg} \cdot \mathrm{mL}^{-1}$ for the assay because in this concentration range we have observed a good MR activity. Figure 7 a shows a representative microscopic image of the hdF $24 \mathrm{~h}$ after treatment with the NPs $\left(c=1 \mathrm{mg} \cdot \mathrm{mL}^{-1}\right)$. There is clear evidence that the cells treated with the NPs compared to untreated cells kept their typically morphology and proliferated normally under standard culture conditions. The granular structures in the picture arise from FCS (cf. untreated cells, Figure S4, Supporting Information File 1). The results of a CellTiter-Glo assay show the viability of hdF $24 \mathrm{~h}$ after treatment of these cells with the NP dispersions (cf. Figure $7 \mathrm{~b}$ ). NP concentrations of $0.5,0.75$ and $1.0 \mathrm{mg} \cdot \mathrm{mL}^{-1}$ yield cell viabilities of more than $80 \%$ with
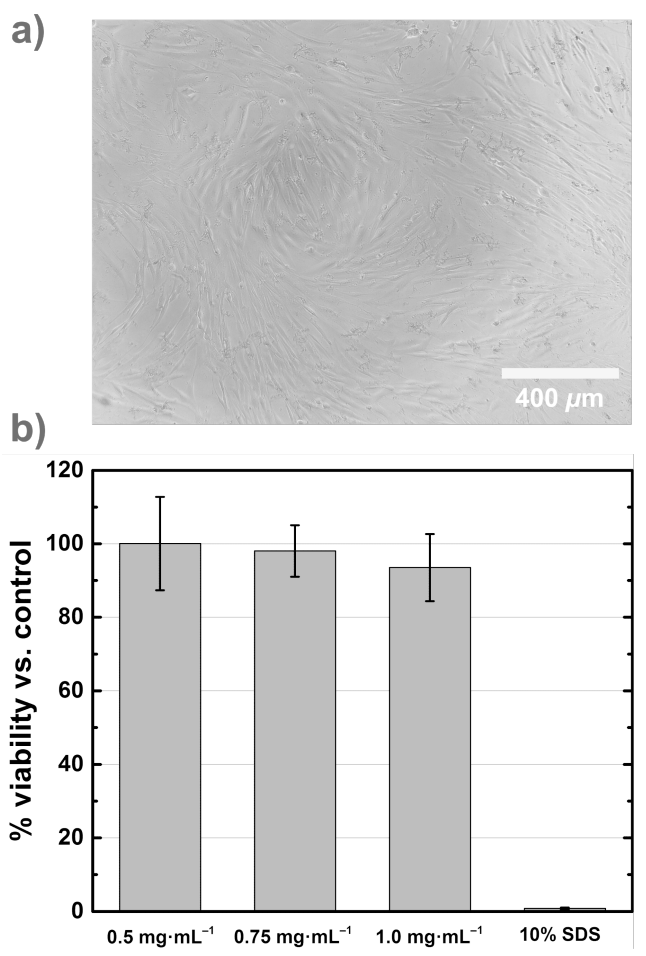

Figure 7: a) Representative microscopic image of hdF $24 \mathrm{~h}$ after treatment with the NPs $\left(c=1 \mathrm{mg} \cdot \mathrm{mL}^{-1}\right)$. b) Cell viability $24 \mathrm{~h}$ after adding $\mathrm{CaF}_{2}:\left(\mathrm{Tb}^{3+}, \mathrm{Gd}^{3+}\right) \mathrm{NPs}$ at concentrations between 0.5 and $1 \mathrm{mg} \cdot \mathrm{mL}^{-1}$ to hdF. $10 \%$ SDS was used for the positive control. All samples have cell viabilities over $80 \%$ and therefore the NPs can be classified as non-cytotoxic $(n=3)$. respect to the positive control. Thus in this concentration range no cytotoxicity of $\mathrm{CaF}_{2}:\left(\mathrm{Tb}^{3+}, \mathrm{Gd}^{3+}\right) \mathrm{NPs}$ is observed on hdF.

\section{Conclusion}

In summary, we have demonstrated a new multifunctional particle system $\mathrm{CaF}_{2}:\left(\mathrm{Tb}^{3+}, \mathrm{Gd}^{3+}\right)$, which was fabricated via a co-precipitation process. TEM, DLS, XRD and ICP-OES examinations deliver a consistent characterization of the NPs. According to TEM and DLS measurements, the mean size of the NPs is in the range of 5-10 $\mathrm{nm}$ and they have a spherical shape. In the XRD diffractogram the crystalline structure of fluorite $\mathrm{CaF}_{2}$ is observable. The outcome of ICP-OES shows a congruent composition of the NPs in all different batches. Hence the results of these characterization methods evidence that the used synthesis was successful and capable of producing the desired particle system. The assumption is that doping with the rare-earth ions $\mathrm{Tb}^{3+}$ and $\mathrm{Gd}^{3+}$ leads to a PL and MR activity. The $\mathrm{Tb}^{3+}$ emission spectrum shows maxima at the expected wavelengths $(489,542,585,621$ and $667 \mathrm{~nm})$. This signifies the successful $\mathrm{Tb}^{3+}$ doping and thus, the NPs are suitable for use as a PL CA. With the second investigated imaging technique MRI we verified the integration of the $\mathrm{Gd}^{3+}$ ions in the $\mathrm{CaF}_{2}$ lattice and the reproducibility of the NP synthesis procedure. Furthermore, we investigated the long-term stability of the relaxivities. In fact, the results for all batches show a decrease of the relaxivity of about $11.6 \%$ after nine months. Finally, the cell viability of the NPs stabilized with Melpers ${ }^{\circledR} 2450$ was evaluated in hdF and we can show that the NP system is biocompatible and non-toxic.

Overall, we have developed a very promising particle system $\mathrm{CaF}_{2}:\left(\mathrm{Tb}^{3+}, \mathrm{Gd}^{3+}\right)$, which can be used as a multimodal CA for two different imaging methods and therefore allows for a more reliable, precise and time efficient diagnosis of diseases.

\section{Experimental Materials}

Calcium chloride $\left(\mathrm{CaCl}_{2}, \geq 95 \%\right)$, ammonium fluoride $\left(\mathrm{NH}_{4} \mathrm{~F}\right.$, p.a.), terbium(III) nitrate pentahydrate $\left(\mathrm{Tb}\left(\mathrm{NO}_{3}\right)_{3} \cdot 5 \mathrm{H}_{2} \mathrm{O}\right.$, $99.9 \%)$ and gadolinium(III) chloride hexahydrate $\left(\mathrm{GdCl}_{3} \cdot 6 \mathrm{H}_{2} \mathrm{O}\right.$, 99\%) were purchased from Sigma-Aldrich and used without further purification.

\section{Synthesis of $\mathrm{CaF}_{2}:\left(\mathrm{Tb}^{3+}, \mathrm{Gd}^{3+}\right) \mathrm{NPs}$}

Following Wang et al., $3.72 \mathrm{~g}$ (33.5 mmol) $\mathrm{CaCl}_{2}, 146 \mathrm{mg}$ ( $340 \mu \mathrm{mol}, 1 \mathrm{~mol} \%$ based on Ca content) $\mathrm{Tb}\left(\mathrm{NO}_{3}\right)_{3} \cdot 5 \mathrm{H}_{2} \mathrm{O}$ and $121 \mathrm{mg}\left(340 \mu \mathrm{mol}, 1 \mathrm{~mol} \%\right.$ based on Ca content) $\mathrm{GdCl}_{3} \cdot 6 \mathrm{H}_{2} \mathrm{O}$ were dissolved in $420 \mathrm{~mL}$ ethanol [26]. $2.5 \mathrm{~g}$ (67.5 mmol) of ammonium fluoride were added under sonification. Subsequently, the solution was stirred at room temperature for $12 \mathrm{~h}$. The resulting precipitate was collected by centrifugation and 
washed with ethanol and deionized water for three times to remove possible impurities such as $\mathrm{CaCl}_{2}$. Then the precipitate was dried at $60{ }^{\circ} \mathrm{C}$ for $12 \mathrm{~h}$ and collected for characterization.

\section{Characterization}

The morphology of the NPs was studied by TEM on a Zeiss EM 900 transmission electron microscope at an acceleration voltage of $200 \mathrm{kV}$. Samples were prepared by dipping 200 mesh copper grids coated with a thin carbon film (Quantifoil Micro Tools $\mathrm{GmbH}$ ) into aggregate-free NP dispersions. The size of the particles was determined by the measurement tools of Fiji. The DLS was measured with a Zetasizer Nano-ZS from Malvern Instruments. The DLS measurement was carried out in aqueous solutions. X-ray diffraction measurements were carried out on a Phillips PW 1730/10 employing $\mathrm{Cu}$ K $\alpha$ radiation. The composition of the NPs was determined by ICP-OES using a Varian Wista Pro spectrometer. The crystallinity of the powder samples was analyzed with a Philips PW 1152. For photoluminescence measurements, a custom-built photospectrometer (S\&I Spectroscopy \& Imaging FluoroVista) was used. The excitation of the $\mathrm{Tb}^{3+}$-related emission spectra was carried out with a $254 \mathrm{~nm}$ UV lamp (Vilber Lourmat VL-4.LC), the emission was detected with a high-speed silicon CCD camera (Princeton Instruments PIXIS256). The spectra were not corrected for the spectral sensitivity of the experimental setup.

\section{MRI measurements}

To guarantee a homogenous distribution within each sample, all tubes were sonicated for five minutes and vortexed afterwards. The MRI examinations took place within the following hour. All measurements were performed at a $1.5 \mathrm{~T}$ system (Magnetom Avanto, Siemens) in combination with a $4+4$ channel multifunctional coil array (NORAS MRI products). The relaxation time constant $T_{1}$ was obtained through a segmented 2D IRSnapshotFlash method $\left(T_{\mathrm{R}} / T_{\mathrm{E}}=8.7 \mathrm{~ms} / 4.8 \mathrm{~ms}\right.$, matrix: $256 \times 176$, inplane resolution: $0.7 \times 0.7 \mathrm{~mm}^{2}$, slice thickness: $20 \mathrm{~mm}$, number of segments: 44 , number of echoes: 128 , $T_{\mathrm{A}}=4.75 \mathrm{~min}$ ) $[45,46]$. Image reconstruction, data fitting and a manually segmentation of the tubes was done offline using Matlab R2012b (The Mathworks). The program used for the statistical analysis was PASW Statistics 18 (IBM).

\section{Biocompatibility}

$\mathrm{CaF}_{2}:\left(\mathrm{Tb}^{3+}, \mathrm{Gd}^{3+}\right)$ NPs were stabilized by shaking the particles in a $20 \mathrm{vol} \%$ Melpers ${ }^{\circledR} 2450$ dispersion in water for $18 \mathrm{~h}$. Afterwards the NPs were centrifuged, washed two times with DI water and finally redispersed in DMEM with $10 \%$ FCS.

The sedimentation studies over $24 \mathrm{~h}$ were carried out by monitoring the absorbance at $700 \mathrm{~nm}$ as a function of time (Shimadzu, UV-3100). The sample $\left(5 \mathrm{mg} \cdot \mathrm{mL}^{-1} \mathrm{NPs}\right.$ in DMEM with $10 \%$ FCS, with or without Melpers ${ }^{\circledR} 2450$ ) was placed into a polystyrene micro cuvette and the absorbance was measured in 20 min time intervals. As the measurement beam entered the cuvette approximately $1.5 \mathrm{~cm}$ from the bottom of the cuvette, the supernatant of the sedimenting sample was measured. As a reference DMEM with 10\% FCS was used. The first measurement was taken as 1.0 and the reference as 0 .

The cell toxicity of the $\mathrm{CaF}_{2}:\left(\mathrm{Tb}^{3+}, \mathrm{Gd}^{3+}\right)$ NPs was investigated in 96-well plates on a subconfluent monolayer culture of hdF. With the CellTiter-Glo luminescent cell viability assay (Promega), based on the quantification of the ATP concentration, the cell viability was examined. The cell line was seeded into 96-well cell-culture plates at a number of $1.47 \cdot 10^{4}$ cells per square centimeter. Dilutions of $\mathrm{CaF}_{2}:\left(\mathrm{Tb}^{3+}, \mathrm{Gd}^{3+}\right) \mathrm{NP}$ samples in the concentration range of $0.5-1 \mathrm{mg} \cdot \mathrm{mL}^{-1}$ in DMEM with $10 \%$ FCS were added in triplicate. Wells containing $10 \%$ sodium dodecyl sulfate (SDS) and untreated hdF in DMEM with $10 \%$ FCS were used as positive and negative control, respectively. After $24 \mathrm{~h}$ of incubation, the CellTiter-Glo reagent was administered per well according to the instructions of the manufacturer. Briefly, the test solutions were removed by washing with PBS buffer, the cells in each well were overlaid with $100 \mu \mathrm{L}$ of basal medium and $100 \mu \mathrm{L}$ of CellTiter-Glo reagent and luminescence was measured after two minutes of shaking and ten minutes incubation at room temperature in a TECAN plate reader (infinite M200, TECAN, Maennedorf, Switzerland). According to DIN EN ISO 10993-5, a more than $20 \%$ deviation of measurement values of treated cells compared to the untreated control was defined as cytotoxic.

\section{Supporting Information}

\section{Supporting Information File 1}

Additional figures and data.

[http://www.beilstein-journals.org/bjnano/content/ supplementary/2190-4286-8-148-S1.pdf]

\section{Acknowledgements}

M. Straßer and J. H. X. Schrauth contributed equally to this work. We thank Prof. Dr. Georg Krohne (Department of Biology, University of Wuerzburg, Germany) for providing the electron microscopy and Kevin Duscher for the support while stabilizing the NPs.

\section{References}

1. Doubrovin, M.; Serganova, I.; Mayer-Kuckuk, P.; Ponomarev, V.; Blasberg, R. G. Bioconjugate Chem. 2004, 15, 1376-1388. doi:10.1021/bc0498572 
2. Park, J.; Yang, J.; Lee, J.; Lim, E.-K.; Suh, J.-S.; Huh, Y.-M.; Haam, S. J. Colloid Interface Sci. 2009, 340, 176-181. doi:10.1016/j.jcis.2009.08.015

3. Sosnovik, D. E.; Nahrendorf, M.; Deliolanis, N.; Novikov, M.; Aikawa, E.; Josephson, L.; Rosenzweig, A.; Weissleder, R.; Ntziachristos, V. Circulation 2007, 115, 1384-1391. doi:10.1161/CIRCULATIONAHA.106.663351

4. Corr, S. A.; Rakovich, Y. P.; Gun'ko, Y. K. Nanoscale Res. Lett. 2008, 3, 87-104. doi:10.1007/s11671-008-9122-8

5. Hu, K.-W.; Jhang, F.-Y.; Su, C.-H.; Yeh, C.-S. J. Mater. Chem. 2009, 19, 2147-2153. doi:10.1039/b815087g

6. Probst, J.; Dembski, S.; Milde, M.; Rupp, S. Expert Rev. Mol. Diagn. 2012, 12, 49-64. doi:10.1586/erm.11.86

7. Chen, J.; Guo, Z.; Wang, H.-B.; Gong, M.; Kong, X.-K.; Xia, P.; Chen, Q.-W. Biomaterials 2013, 34, 571-581. doi:10.1016/j.biomaterials.2012.10.002

8. Zheng, W.; Zhou, S.; Chen, Z.; Hu, P.; Liu, Y.; Tu, D.; Zhu, H.; Li, R.; Huang, M.; Chen, X. Angew. Chem., Int. Ed. 2013, 52, 6671-6676. doi:10.1002/anie.201302481

9. Zheng, W.; Zhou, S.; Chen, Z.; Hu, P.; Liu, Y.; Tu, D.; Zhu, H.; Li, R.; Huang, M.; Chen, X. Angew. Chem. 2013, 125, 6803-6808. doi:10.1002/ange.201302481

10. Lebugle, A.; Pellé, F.; Charvillat, C.; Rousselot, I.; Chane-Ching, J. Y. Chem. Commun. 2006, 606-608. doi:10.1039/b515164c

11. Kim, E. J.; Choi, S.-W.; Hong, S.-H. J. Am. Ceram. Soc. 2007, 90, 2795-2798. doi:10.1111/j.1551-2916.2007.01791.x

12. Petoral, R. M., Jr.; Söderlind, F.; Klasson, A.; Suska, A.; Fortin, M. A.; Abrikossova, N.; Selegård, L.; Käll, P.-O.; Engström, M.; Uvdal, K. J. Phys. Chem. C 2009, 113, 6913-6920. doi:10.1021/jp808708m

13. Ashokan, A.; Menon, D.; Nair, S.; Koyakutty, M. Biomaterials 2010, 31, 2606-2616. doi:10.1016/j.biomaterials.2009.11.113

14. Pandurangappa, C.; Lakshminarasappa, B. N. Opt. Commun. 2012, 285, 2739-2742. doi:10.1016/j.optcom.2012.01.054

15. Wang, J.; Miao, W.; Li, Y.; Yao, H.; Li, Z. Mater. Lett. 2009, 63, 1794-1796. doi:10.1016/j.matlet.2009.05.047

16. Pandey, C.; Bhasin, J. K.; Dhopte, S. M.; Muthal, P. L.; Moharil, S. V. Mater. Chem. Phys. 2009, 115, 804-807. doi:10.1016/j.matchemphys.2009.02.027

17. Lim, S. F.; Riehn, R.; Ryu, W. S.; Khanarian, N.; Tung, C.-k.; Tank, D.; Austin, R. H. Nano Lett. 2006, 6, 169-174. doi:10.1021/nI0519175

18. Wang, Z. L.; Quan, Z. W.; Jia, P. Y.; Lin, C. K.; Luo, Y.; Chen, Y.; Fang, J.; Zhou, W.; O'Connor, C. J.; Lin, J. Chem. Mater. 2006, 18, 2030-2037. doi:10.1021/cm052360x

19. Zeng, J.-H.; Su, J.; Li, Z.-H.; Yan, R.-X.; Li, Y.-D. Adv. Mater. 2005, 17, 2119-2123. doi:10.1002/adma.200402046

20. Wei, Y.; Lu, F.; Zhang, X.; Chen, D. Chem. Mater. 2006, 18, 5733-5737. doi:10.1021/cm0606171

21. Park, Y. I.; Kim, J. H.; Lee, K. T.; Jeon, K.-S.; Na, H. B.; Yu, J. H.; Kim, H. M.; Lee, N.; Choi, S. H.; Baik, S.-I.; Kim, H.; Park, S. P.; Park, B.-J.; Kim, Y. W.; Lee, S. H.; Yoon, S.-Y.; Song, I. C.; Moon, W. K.; Suh, Y. D.; Hyeon, T. Adv. Mater. 2009, 21, 4467-4471. doi:10.1002/adma.200901356

22. Chen, Z.; Liu, Z.; Liu, Y.; Zheng, K.; Qin, W. J. Fluorine Chem. 2012, 144, 157-164. doi:10.1016/j.jfluchem.2012.08.009

23. Feldmann, C.; Roming, M.; Trampert, K. Small 2006, 2, 1248-1250. doi:10.1002/smll.200600140

24. Zhi, G.; Song, J.; Mei, B.; Zhou, W. J. Alloys Compd. 2011, 509, 9133-9137. doi:10.1016/j.jallcom.2011.06.084

25. Kumar, G. A.; Chen, C. W.; Riman, R. E. Appl. Phys. Lett. 2007, 90, 93123. doi:10.1063/1.2392284
26. Wang, F.; Fan, X.; Pi, D.; Wang, M. Solid State Commun. 2005, 133, 775-779. doi:10.1016/j.ssc.2005.01.014

27. Zahedifar, M.; Sadeghi, E.; Harooni, S. Nucl. Instrum. Methods Phys. Res., Sect. B 2012, 291, 65-72. doi:10.1016/j.nimb.2012.09.013

28. Dong, N.-N.; Pedroni, M.; Piccinelli, F.; Conti, G.; Sbarbati, A.; Ramírez-Hernández, J. E.; Maestro, L. M.; Iglesias-de la Cruz, M. C.; Sanz-Rodriguez, F.; Juarranz, A.; Chen, F.; Vetrone, F.; Capobianco, J. A.; Solé, J. G.; Bettinelli, M.; Jaque, D.; Speghini, A. ACS Nano 2011, 5, 8665-8671. doi:10.1021/nn202490m

29. Wang, G.; Peng, Q.; Li, Y. J. Am. Chem. Soc. 2009, 131, 14200-14201. doi:10.1021/ja906732y

30. Grass, R. N.; Stark, W. J. Chem. Commun. 2005, 1767-1769. doi:10.1039/b419099h

31. Tian, Y.; Yu, J.-C.; Qi, X.-H.; Wu, X.-W.; Hua, R.-N.; Fan, S.-D. J. Mater. Sci.: Mater. Electron. 2009, 20, 439-444. doi:10.1007/s10854-008-9748-4

32. Bensalah, A.; Mortier, M.; Patriarche, G.; Gredin, P.; Vivien, D. J. Solid State Chem. 2006, 179, 2636-2644. doi:10.1016/j.jssc.2006.05.011

33. Ritter, B.; Krahl, T.; Rurack, K.; Kemnitz, E. J. Mater. Chem. C 2014, 2, 8607-8613. doi:10.1039/C4TC01073F

34. Binnemans, K.; Van Deun, R.; Görller-Walrand, C.; Adam, J. L. J. Non-Cryst. Solids 1998, 238, 11-29. doi:10.1016/S0022-3093(98)00540-7

35. Hou, Z.; Wang, L.; Lian, H.; Chai, R.; Zhang, C.; Cheng, Z.; Lin, J. J. Solid State Chem. 2009, 182, 698-708. doi:10.1016/j.jssc.2008.12.021

36. Gaft, M.; Panczer, G.; Reisfeld, R.; Uspensky, E. Phys. Chem. Miner. 2001, 28, 347-363. doi:10.1007/s002690100163

37. Boutinaud, P.; Mahiou, R.; Cousseins, J. C. J. Lumin. 1997, 72-74, 318-320. doi:10.1016/S0022-2313(96)00172-X

38. Reichenbach, J. R.; Hackländer, T.; Harth, T.; Hofer, M.; Rassek, M.; Mödder, U. Eur. Radiol. 1997, 7, 264-274. doi:10.1007/s003300050149

39. Allouni, Z. E.; Cimpan, M. R.; Høl, P. J.; Skodvin, T.; Gjerdet, N. R. Colloids Surf., B 2009, 68, 83-87. doi:10.1016/j.colsurfb.2008.09.014

40. Ji, Z.; Jin, X.; George, S.; Xia, T.; Meng, H.; Wang, X.; Suarez, E.; Zhang, H.; Hoek, E. M. V.; Godwin, H.; Nel, A. E.; Zink, J. I. Environ. Sci. Technol. 2010, 44, 7309-7314. doi:10.1021/es100417s

41. Bihari, P.; Vippola, M.; Schultes, S.; Praetner, M.; Khandoga, A. G.; Reichel, C. A.; Coester, C.; Tuomi, T.; Rehberg, M.; Krombach, F. Part. Fibre Toxicol. 2008, 5, 14. doi:10.1186/1743-8977-5-14

42. Koch, S.; Kessler, M.; Mandel, K.; Dembski, S.; Heuzé, K.; Hackenberg, S. Colloids Surf., B 2016, 143, 7-14. doi:10.1016/j.colsurfb.2016.03.010

43. Vaisman, L.; Wagner, H. D.; Marom, G. Adv. Colloid Interface Sci. 2006, 128-130, 37-46. doi:10.1016/j.cis.2006.11.007

44. Promega 2012, Technical Bulletin of CellTiter-Glo® Luminescent Cell Viability Assay.

https://www.promega.de/-/media/files/resources/protocols/technical-bull etins/0/celltiter-glo-luminescent-cell-viability-assay-protocol.pdf (accessed June 22, 2017).

45. Haase, A.; Frahm, J.; Matthael, D.; Hänicke, W.; Merboldt, K.-D. J. Magn. Reson. 1986, 67, 258-266. doi:10.1016/0022-2364(86)90433-6

46. Haase, A. Magn. Reson. Med. 1990, 13, 77-89. doi:10.1002/mrm.1910130109 


\section{License and Terms}

This is an Open Access article under the terms of the Creative Commons Attribution License

(http://creativecommons.org/licenses/by/4.0), which permits unrestricted use, distribution, and reproduction in any medium, provided the original work is properly cited.

The license is subject to the Beilstein Journal of Nanotechnology terms and conditions:

(http://www.beilstein-journals.org/bjnano)

The definitive version of this article is the electronic one which can be found at:

doi:10.3762/bjnano.8.148 